\title{
Did macro structural effects of the Great Recession impact substance abuse outpatient treatment completion rates for minorities?
}

\author{
Kathleen Ayako Anangwe', Lucas Enrique Espinoza², Luis Enrique Espinoza ${ }^{3}$ \\ $\mathrm{PhD}$, Department of Philosophy, The University of Nairobi, Nairobi, Kenya ${ }^{1}$ \\ $\mathrm{PhD}$, Department of Criminal Justice, The University of Texas Rio Grande Valley, Edinburg, TX 78539 \\ $\mathrm{PhD}, \mathrm{MPH}, \mathrm{CHES}^{\circledR}, \mathrm{CPH}$, Department of Health Studies, Texas Woman's University, Denton, TX \\ $76204^{3}$
}

\begin{abstract}
Whereas studies have documented health disparities among ethnic minorities occasioned by poor access and bias in healthcare at local levels, there has been little discussion linking globalization impacts to the health outcomes of ethnic minorities. Specifically, research focused on ethnic minorities seeking treatment for substance abuse. The great recession of the past decade in the United States (2008-2010), provides an adequate backdrop against which the completion of substance abuse treatments among minorities can be linked to global forces whose effects on their social realities can be estimated. Data from the Treatment Episode Datasets-Discharge (TEDSD) representing outpatient substance abuse treatment centers across the United States is used. All treatment users were classified by race. We use multivariate logistic regression to estimate the effect of the great recession by weighing whether racial-ethnic differences, gender and region influence discharge completion rates. We find that, ethnic minorities are less likely to access substance abuse treatment, and less likely to complete substance abuse treatment. The regional analysis gives insight into the broader impacts of the recession's effect when we find that individuals from the South were generally less likely to complete discharge services when all regions are considered. Overall, primary substance in use, age, and education, inspired by global contexts, invariably explain the rates of successful completion. We conclude that outpatient completion rates for substance abuse are impacted negatively by macro processes such the great recession.
\end{abstract}

Keywords: substance abuse treatment, global forces, ethnic minorities, health disparities, completion rates. 


\title{
International Conference on Advanced Research in SOCIAL SCIENCES
}

\author{
March 7-9, 2019, London - United Kingdom
}

\section{Introduction}

Although successfully completing treatment is a major objective of clients receiving substance abuse treatment, among ethnic minorities the influence of psychosocial stressors and socio-economic adjustment resulting from macro processes such as economic downturn and subsequent recession remain understudied (Arndt, Acion and White 2013; Cole, Logan, and Walker 2011). It is documented in sociological studies that ethnic minorities are perversely affected by macro complex socio- economic contexts that diminish their already vulnerable health status and wellbeing (Williams et al. 2010).

As such, studies have tended to focus on their participation in health systems but there has been little to no focus on the outcomes of their involvement in treatment programs specifically with regards to the completion of substance abuse treatment. Substance abuse refers to the ingestion of psychoactive substances such as cigarettes, alcohol and illicit drugs which alter behavior, perception, cognitive or motor skills (American Psychiatric Association 2010; Mezuk et al. 2010; World Health Organization 2017). It is a concern to sociologists because apart from being considered an antisocial behavior, it easily leads to addiction, and other public health problems such as crime, adverse health consequences, risky behavior, violence, suicide, low selfesteem, physical withdrawal and economic hardship (Fox, Hong, and Sinha 2008; Sinha 2008). It is noted that once addiction occurs, among minorities it causes greater harm because it affects an individual's, and their family's economic stability through dependence on healthcare systems because of poor health (Moos 2008).

Studies concerning minorities are an attempt to overcome their underrepresentation, and provide significant insight into the successful or unsuccessful outcomes of programs such as the substance abuse treatment one within the health systems of the United States (Bartlett et al. 2005; Sheikh, 2005). The different treatments for substance abuse are majorly conducted inpatient and outpatient. Inpatient programs provide a strict regimen keeping clients in a routine of supervision, observation, and support by medical professionals twenty-four hours a day. The inpatient programs are used as a way of providing services to those people who possess severe dysfunction in their lives as a result of the substance abuse.

Furthermore, these programs are premised on enhancing responsibility and reliability in the patient as part of the expected wellness outcome. Conversely, outpatient programs provide a solution to clients with moderate symptoms to maintain their daily involvement in social activity at the family and, in formal and informal environments (Substance Abuse and Mental Health Services Administration 2006). In other words, outpatient programs require a range of involvement on the part of the client and includes evaluation, detoxification, and referral services. However, the program needs clients to maintain a commitment and conform to the stipulated regulations requiring that their lives be organized in ways that promote the exclusion of substance abuse, but more critically that they embrace anonymity given that they have to leave their day-today activities and environments to attend sessions at the hospital. 


\section{International Conference on Advanced Research in SOCIAL SCIENCES}

March 7-9,2019, London - United Kingdom

Successful completion of substance abuse treatment is desirable at two levels, first, at the institutional level because it reduces pressure on medical facilities through fewer readmissions and personnel costs. Second, at the individual level because it gives rise to steady employment, income and reduced criminal affiliation. These are salient positive consequences that are desirable (Atun 2004). Additionally, state level systems are also able to assess their substance abuse programs through effective monitoring and evaluation of clients thereby continuously making requisite improvements to enhance these programs (Arndt et al. 2013; Evans, Li, and Hser 2009; Garnick et al. 2009; National Healthcare Disparities Report, 2011; The TOPPS-II Interstate Cooperative Study Group 2003).

More specifically however, although there is an established correlation between the performance of an economy and its influence on the access, use and provision of health programmes (Bor et al. 2011) little is known about the economic, social and psychological wellbeing of minorities accessing substance abuse treatment following the recent "Great Recession" in the United States which began in 2007 and ended in 200 (Grusky, Western, and Wimer 2011a; Krugman and Wells 2010). In addition, completion rates of minority outpatient treatment in this recession period remains unknown. The underestimation of the recession's scope of effects is largely to blame, yet an analysis cognizant of its significance beyond the historical and economic consequence can provide invaluable insights structurally, and systematically on inconsistent social behavior post treatment. Already minorities are considered vulnerable following their social, economic and political disadvantage (Lo and Cheng 2012; Lo, Cheng, and Howell 2014; Mirowsky and Ross 2003) yet apart from scholarly explanation of disparities in access to a varied amount of healthcare services, there is scarce evidence of completion rates in organized health programs.

It has been specifically documented that the "Great Recession" further elevated the vulnerability of minorities following an upsurge in existing crises notably through an increase in unemployment of up to $10 \%$ by 2009 , poverty, divorce, multigenerational living arrangements, homelessness, alcohol dependence, binge drinking and lack of medical insurance (Bor et al. 2013; Bureau of Labor Statistics 2012; Burke and Alpert, 2010; Catalano et al. 1993; Eliason and Storrie 2009; Fligstein \& Goldstein 2011; Grusky et al. 2011; National Bureau of Economic Research 2010). Historical evidence depicts the resultant deteriorating macro-micro conditions following a recession as reason for an upsurge in emergency room visits and hospitalization after substance abuse (Bor et. al. 2013; Dee 2001). Yet when considered together, this negative outcome can be mitigated further through the successful completion of substance abuse treatment programme (Moos 2008; Volkow 2016; Walton et al. 2002). Additionally, successful completion of programmes such as the substance abuse treatment one will likely diffuse the resultant effects on minorities of a reduction in funding due to budgetary shortfalls of the recession period (Doward 2011).

In terms of race categories recent research indicates that ethnic minority groups are less likely than White clients to access substance abuse treatment (Lo and Cheng 2011) and to successfully complete treatment in the event that they access it (Ardnt et al. 2013; Ball et al. 2006; Cooper, Macmaster and Rasch 2010). However, there is a dearth of literature explaining specific 


\section{International Conference on Advanced Research in SOCIAL SCIENCES}

March 7-9,2019, London - United Kingdom

factors accounting for the existing substance abuse treatment completion rates among minorities which are greater when compared to Whites (Danziger, Chavez and Cumberworth, 2012; Grusky, Western, and Wimer 2011a, Grusky, Western, and Wimer 2011b). Despite anecdotal assertion that during hard economic times, all ethnic/ racial groups face similar challenges, a large amount of multidisciplinary scholarly evidence states that a convergence of various factors riding on existing vulnerabilities interferes with positive health engagements and outcomes among minority racial/ethnic groups (Danziger, Chavez and Cumberworth, 2012).

This study therefore aims at examining the race/ethnicity trends in successful completion of ambulatory, non-intensive substance abuse outpatient treatment completion rates at the level of the state. Acknowledging that psychosocial factors exacerbated by the great recession are major pathways determining trends in outpatient substance abuse completion rates, we examine their effect on the reasons for discharge among the different groups of minorities by focusing on two research questions, first, To what extent are completion rates influenced by racial, ethnic differences?; and second, Are outpatient substance abuse completion rates influenced by region in the US?

Social stress has been associated historically with drug use, alcohol dependency and other mental health issues. Recently, however, social factors such as socioeconomic status, race/ethnicity and gender are being associated with substance use disorders and relapse (Wahler, 2012; Walton et al., 2003). By highlighting these social factors, there emerges an additional discussion on the location of the outpatient treatment provider whose salience in sociological study cannot be overemphasized. Similarly, the social conditions framed within a particular region, directly influence users and nuance differences in completion rates.

In this study, the use of region further captures the consideration that optimal functioning of the various healthcare systems located in any region and minority incomes depend on the Gross Domestic Product (GDP) (Chakroun, 2009; Narayan and Narayan 2008; Walton, Reischl and Ramanathan 1995). Thus, the larger the GDP of a region, the better the treatment offered and the higher the income of the minority substance user which enables the individual to access quality sustainable treatment and adhere to the treatment plan to completion (Lago-Peñas, CantareroPrieto and Blázquez-Fernández, 2013). Indeed, Gerdtham and Löthgren (2000) in a panel cointegration for twenty-one Organisation for Economic Co-operation and Development countries found that both health care expenditure and gross domestic product are non-stationary and integrated. In sum, unemployment and stress are unlikely to be factors in discontinued substance abuse treatment completion in regions with high GDP.

Pearlin (1989) expounds upon that social stress theory provides connections through an analysis of relationships among social characteristics which incubate perceived disadvantage, stress which in the case of this study is aggravated by the recession, and the subsequent distress outcomes that produce secondary effect (Wahler 2012). In the theory, he further seeks to understand social patterns among stress and distress (Pearlin 1989). It has been determined in research that minority status is correlated with increased stress due to greater experiences of discrimination, lower sense of control, and less power and status all of which are outcomes likely in a recession (Mirowsky and Ross 2003). Additionally, Grusky and Weisshaar (2001) found in 


\section{International Conference on Advanced Research in SOCIAL SCIENCES}

March 7-9,2019, London - United Kingdom

research that social factors produce stratification in which social disadvantages which cause stress are disproportionately dispersed across the strata even though other social factors such as marital status and age may the circumstances caused by these disadvantages (Cole, Logan and Walker 2011: Tenorio and Lo 2011).

Pearlin (1989) believed that the process of stress building could produce threat, conflict and /or harmony. He further extended the ideas of other stress theorists by looking at the stress process following a stressful event to see what strain it may have caused (Pearlin et al. 1981). Subsequently, this current research uses the social stress perspective to determine the trends in substance abuse discharge status following outpatient treatment among minorities in the United States during a period of economic difficulty- namely the great recession.

Materials and Methods

\section{Sample}

The Substance Abuse and Mental Health Services Administration requests admission and discharge information from and public and private treatment facilities receiving public funding in the US (Center for Behavioral Health Statistics and Quality 2016). The treatment facilities include those in urban and rural counties. These data are made available as the Treatment Episode Datasets-Discharge (TEDS-D) (U.S. Department of Health and Human Services 2015).

While this dataset includes all admissions and discharges rather than individual episodes, we selected only those records that indicated that an individual had no prior admissions at a treatment facility. Although this information is self-reported; states do have the ability to use their electronic system to fill in the variable provided the records are available. Our selection restricted the admissions providing a non-duplicative total of individuals admitted and discharged for treatment. The concatenated 2006-2011 dataset was used for this study and represents all reported discharges from ambulatory, non-intensive outpatient treatment occurring within this time period. Alabama, Arizona, New Mexico, Pennsylvania, and Wisconsin did not contribute to this dataset since they were missing critical variables from their state files. Because these data represent public information and there is no subject identification, the university's Institutional Review Board exempted this study. The sample also included only records which had valid responses for all variables of interest.

\section{Measures}

Discharge status, the outcome variable, was coded by treatment agency staff as: completed treatment versus all other reasons (i.e., left against professional advice, incarcerated, transferred, and other). At admission, agency staff identified the patient's primary problem substance by interview (i.e., the precipitating substance causing the most problems). Staff recorded secondary and tertiary problem substances, as required, together with additional admission data including demographic information and referral sources.

Our main independent variables are based on the race/ethnic groups that were determined by self-report to race and ethnicity questions; and region. Whites included all Caucasians who did 


\section{International Conference on Advanced Research in SOCIAL SCIENCES}

March 7-9,2019, London - United Kingdom

not indicate Hispanic/Latino ethnicity. The Hispanic group included all admissions indicating a Hispanic ethnicity, and did not indicate their race as Black/African American. The fourth race group included all persons who did not identify as White, Black or Hispanic. White was our reference category in the logistic regression models. Region is based on the Census 1970 designations of Northeast, Midwest, South and West. Those people who lived outside in U.S. territories were not included in our sample.

Due to confidentiality concerns, age and education were categorized. Sex was determined by self-report as either being male or female. Sex was dummy coded with male being designated as 1 , and female as zero. At admission, agency staff identified the patient's primary substance problem (i.e., the precipitating substance causing the most problems [none, alcohol, cocaine/crack, marijuana/hashish, heroin, etc.]) by interview. Because of low percentages, several drug categories were collapsed for analysis. Non-prescription methadone $(0.3 \%)$ was combined with other opiates and synthetics $(6.5 \%)$. Phencyclidine [PCP] $(0.2 \%)$ was collapsed with other hallucinogens $(0.1 \%)$. Other amphetamines $(0.6 \%)$ and other stimulants $(0.041 \%)$ were merged. Benzodiazepines $(0.7 \%)$, other non-benzodiazepine tranquilizers $(0.023 \%)$, barbiturates $(0.044 \%)$, and other non-barbiturate sedatives or hypnotics $(0.2 \%)$ were merged. Inhalants $(0.1 \%)$ and over-the-counter medications $(0.044 \%)$ were added to an 'Other' category.

Insurance was determined by self-report. It was categorized by having private insurance, Medicaid, Medicare/other, or no insurance. Other predictors included marital status, employment status, or living arrangement. Marital status was categorized as never married, currently married, separated and divorced/widowed. Employment status was categorized by full-time, part-time, unemployed and not employed. Living arrangements was categorized as homeless, dependent living or independent living. Source of income or support was defined as having a salary, being on public assistance, living off retirement/disability, other and none. We dummy coded our year variables in order to the test the nonlinear effects of time on discharge status. We coded the 6 years (2006-2011; excluding 2007) as dummy variables. We used 2007 as our reference category in our logistic regression models because this was the year the "Great Recession" began.

\section{Statistical Analysis}

All data analyses were conducted using SPSS 23.0. We began with the descriptive analysis where we present the percentages and standard deviations for all the variables for this study. Since our dependent variable was dichotomous in nature, successful completion vs. all other reasons, we used logistic regression to run our models. An initial logistic regression model was performed with the independent variables of interest; a multivariate minority logistic regression model added the control variables to the independent variables.

\section{Results}

\section{Descriptive Analysis}

Table I contains the demographic characteristics of the sample. Approximately half of the sample $(50.5 \%)$ had successful discharge status from a mental health facility. The majority of the 


\section{International Conference on Advanced Research in SOCIAL SCIENCES}

March 7-9, 2019, London - United Kingdom

sample was White $(63.3 \%)$, followed by Black (18.6\%). Most of the respondents lived in the Southern region of the United States (37.8\%), 66.2\% were male, and 43.7\% slightly less than half had a primary substance problem of alcohol. Approximately $28 \%$ of the sample was aged between 25-34 years old. More than $60 \%$ of the sample had 12 years or more of education and bout twothirds were unemployed, with about the same percentage (67.6\%) living independently. A substantial part of the sample had never been married (59.6\%), and had no insurance (65.8\%).

[Table I]

\section{Racial-Ethnic Differences}

In response to research question one, after adjusting for demographics and other completion rate characteristics, there was a statistically significant relationship between racial/ethnic differences and successful treatment discharge (Table II). Blacks were less likely than Whites to achieve successful discharge status ( $\mathrm{OR}=0.846$, [95\% confidence interval [CI]: 0.838-0.854], $\mathrm{p}<0.001)$. However, Hispanics were more likely than Whites to successfully complete treatment $(\mathrm{OR}=1.206$, [95\% CI: 1.190-1.222], $\mathrm{p}<0.001)$. Asian or Pacific Islanders were as likely as Whites to successfully complete treatment while Natives of the US were less likely than Whites to successfully complete treatment ( $\mathrm{OR}=1.074$, [95\% CI: 1.036-1.115], $\mathrm{p}<0.05$; $\mathrm{OR}=0.891$, [95\% CI: 0.876-0.906], $\mathrm{p}<0.001$, respectively). Those clients that were identified as being an 'other race' were more likely than whites to successfully complete treatment ( $\mathrm{OR}=1.042$, [95\% CI: 1.029-1.055], p<0.001).

[Table II]

\section{Regional Differences}

To answer our second research question, after adjusting for demographics and other completion rate characteristics, there was a statistically significant relationship between region and completion rates, such that those who lived in the Northeast region were more likely to complete treatment discharge than those clients who live in the South $(\mathrm{OR}=1.324$, [95\% CI: 1.309-1.339], $\mathrm{p}<0.001)$. Substance abuse clients that lived in the Midwest region were less likely than those who lived in the South to complete treatment discharge (OR=0.619, [95\% CI: 0.6140.624], $\mathrm{p}<0.001)$. Similarly, clients that lived in the Western region were more likely to complete discharge status than those that live in the South (OR=1.013, [95\% CI: 1.004-1.022], $\mathrm{p}<0.001)$.

\section{Client Factors}

The primary substance of abuse seemingly affected completion rates. All primary substances statistically impacted successful discharge status (Table 2). Clients older than 12-17 years of age were less likely to complete treatment than those clients aged 12-17 years old, except for those who were 55 years or older who were most likely to complete rehabilitation treatment $(\mathrm{OR}=1.225$, [95\% CI: 1.199-1.251], $\mathrm{p}<0.001)$. Clients with a higher education, employed fulltime, currently married, and having private insurance were most likely to successfully complete treatment than those who did not meet all the aforementioned criteria. 


\section{International Conference on Advanced Research in SOCIAL SCIENCES}

\section{Discussion}

The analyses demonstrated that the sample varies consistently and considerably given the successful discharge for a significant number of minority based individuals. However, client factors specifically demographics, and institutional factors namely regulations, polices, and procedures are key facilitators to securing mental health access, substance abuse services, and healthcare insurance (Arndt et al., 2013). This is consistent with current literature which indicates that minorities are less likely to access treatment, and complete treatment fully (Ardnt, et al. 2013; Ball et al. 2006; Cooper et al. 2010; Lo \& Cheng 2011). Moreover, we are not aware of any other studies and/or current research trends that examine completion rates and racial-ethnic differences. Additionally, the differences that occur among racial-ethnic groupings must be dealt with at the state level to assess and resolve existing disparities.

Regional disparities were positive for the Northeast and West, yet not so for the Midwest. This indicates that overall those in the South were less likely to complete discharge services. Thus, there is a regional experience with completing treatment. The largest disparity occurs in the Midwest and displays a geographic pattern for the Northeast, and West. This study controlled for gender, primary substance, age, education, employment status, living arrangement, marital status, health insurance, and year of treatment. It is presumed that these differences may reflect organizational effects (Atun, 2004). Other factors and contributing aspects that may impact the completion of treatment, treatment access, the racial-ethnic background of the agency and the mandate according to social services. Though various studies on treatment completion examine the client based characteristics and the perception of treatment, the paucity of studies examining the feelings, attitudes, and affect toward the agency organization in regards to support and availability of services indicates an existing knowledge and attitudes lacunae in the area of treatment completion

Evidence indicates however that those individuals seeking to improve their health outcomes by accessing substance abuse mitigation services differ according to region. Further, lower aspects of successful completion towards discharge might be contributed to by other criteria such as housing, employment, health insurance and other criteria which carry more impact for lower income individuals who in many cases are likely to be ethnic minorities (Arndt et al. 2013; Cole, Logan, and Walker 2011). Several limitations are present in this study. There are likely inconsistencies in the data which might affect the overall accuracy of analysis, since each facility they may hold different interpretations of what a discharge entails. However since the sample included only those clients who sought services offered, the inaccuracy was moderated. Furthermore, although regional variability appears to be evidenced, nuances within each region that might give salience to discussion on inconsistencies of substance abuse completion rates are obscured.

\section{Conclusion}

Overall, a host of issues impact the racial-ethnic differences in successful completion toward outpatient treatment discharge for clients of substance abuse in the United States specifically 


\section{International Conference on Advanced Research in SOCIAL SCIENCES}

March 7-9,2019, London - United Kingdom

during hard economic times such as recessions. The current paper focused on race/ethnicity trends in successful completion of ambulatory, non-intensive substance abuse outpatient treatment at the level of the state. Further research at the national and organization based levels should be pursued to determine macro and meso level factors that impact completion rates of substance abuse outpatient treatment facilities when critical and debilitating macro level contexts such as recessions dictate health outcomes. Since completion rates are impacted by client based characteristics which expand the racial-ethnic disparity reports, it should be noted that the great recession which brought about economic challenges exacerbated the disparities even further. Moreover, it is possible that regional differences exist which influence these completion rates nationally.

\section{Conflict of Interest Statement}

The authors of this study declare they do not have any conflicts of interest.

\section{References}

American Psychological Association. "Substance Use Disorders." Advocacy Monitor on Psychology. 2018. http://www.apa.org/advocacy/substance-use/index.aspx.

Arndt, Stephan, Laura Acion, and Kristin White. "How the States Stack Up: Disparities in Substance Abuse Outpatient Treatment Completion Rates for Minorities." Drug and Alcohol Dependence132, no. 3 (2013): 547-54. doi:10.1016/j.drugalcdep.2013.03.015.

Atun, Rifat. What Are the Advantages and Disadvantages of Restructuring a Health Care System to Be More Focused on Primary Care Services? Report. World Health Organization. Health Evidence Network (HEN). WHO Regional Office for Europe, 2004.

Ball, Samuel A., Kathleen M. Carroll, Monica Canning-Ball, and Bruce J. Rounsaville. "Reasons for Dropout from Drug Abuse Treatment: Symptoms, Personality, and Motivation." Addictive Behaviors31, no. 2 (2006): 320-30. doi:10.1016/j.addbeh.2005.05.013.

Bartlett, C., L. Doyal, S. Ebrahim, P. Davey, M. Bachmann, M. Egger, and P. Dieppe. "The Causes and Effects of Socio-demographic Exclusions from Clinical Trials." Health Technology Assessment9, no. 38 (2005). doi:10.3310/hta9380.

Bor, Jacob, Sanjay Basu, Adam Coutts, Martin Mckee, and David Stuckler. "Alcohol Use During the Great Recession of 2008-2009." Alcohol and Alcoholism48, no. 3 (2013): 343-48. doi:10.1093/alcalc/agt002.

Bureau of Labor Statistics. "National Occupational Employment and Wage Estimates." 2012. http://www.bls.gov/oes/2012/may/oes_nat.htm.

Burke, Kerry, and Lukas I. Alpert. "Alcohol-related Emergency Room Visits Skyrocket in New York: 74,000 in 2009." NY Daily News, 2010. http://www.nydailynews.com/new-york/alcoholrelated-emergency-room-visits-skyrocket-new-york-74-000-2009-article-1.453643. 


\section{International Conference on Advanced Research in SOCIAL SCIENCES}

March 7-9,2019, London - United Kingdom

Catalano, Richard F., J. David Hawkins, Claudia Krenz, Mary Gillmore, Diane Morrison, Elizabeth Wells, and Robert Abbott. "Using Research to Guide Culturally Appropriate Drug Abuse Prevention." Addictive Behaviors: Readings on Etiology, Prevention, and Treatment., 1993, 857-74. doi:10.1037/10248-033.

Center for Behavioral Health Statistics and Quality. "Key substance use and mental health indicators in the United States: Results from the 2015 National Survey on Drug Use and Health (HHS Publication No. SMA 16-4984, NSDUH Series H-51)", 2016. http://www.samhsa.gov/data/

Chakroun, Mohamed. "Health Care Expenditure and GDP: An International Panel Smooth Transition Approach." International Journal of Economics 4, no. 1 (2010): 189-200. https://ssrn.com/abstract=1369153.

Cole, Jennifer, T.K. Logan, and Robert Walker. "Social Exclusion, Personal Control, Selfregulation, and Stress among Substance Abuse Treatment Clients." Drug and Alcohol Dependence113, no. 1 (2011): 13-20. doi:10.1016/j.drugalcdep.2010.06.018.

Cooper, R. Lyle, Samuel Macmaster, and Randolph Rasch. "Racial Differences in Retention in Residential Substance Abuse Treatment: The Impact on African American Men." Research on Social Work Practice20, no. 2 (2009): 183-90. doi:10.1177/1049731509338936.

Danziger, Sheldon, Koji Chavez, and Erin Cumberworth. Poverty and the Great Recession. Stanford, CA: Stanford Center on Poverty and Inequality, 2012.

Dee, Thomas S. "Alcohol Abuse and Economic Conditions: Evidence from Repeated Crosssections of Individual-level Data." Health Economics10, no. 3 (2001): 257-70. doi:10.1002/hec.588.

Doward, Jamie. "Drug Service Cutbacks Have a 'devastating Impact' on Young Addicts, Claim Charities." The Guardian, July 23, 2011. https://www.theguardian.com/society/2011/jul/24/drugcharities-devastating-impact-cuts.

Eliason, Marcus, and Storrie Donald. "Job Loss Is Bad for Your Health - Swedish Evidence on Cause-specific Hospitalization following Involuntary Job Loss." Social Science \& Medicine68, no. 8 (2009): 1396-406.

Evans, Elizabeth, Libo Li, and Yih-Ing Hser. "Client and Program Factors Associated with Dropout from Court Mandated Drug Treatment." Evaluation and Program Planning32, no. 3 (2009): 204-12. doi:10.1016/j.evalprogplan.2008.12.003.

Fligstein, Neil, and Adam Goldstein. Catalyst of Disaster: Subprime Mortgage Securitization and the Roots of the Great Recession. Working paper. Institute for Research on Labor and Employment, UC Berkley. 2011. 1-43.

Fox, H.C., KA. Hong, and R. Sinha. "Difficulties in Emotion Regulation and Impulse Control in Recently Abstinent Alcoholics Compared with Social Drinkers." Addictive Behaviors 33, no. 2 (2008): 388-94. doi:10.1016/j.addbeh.2007.10.002.

Garnick, Deborah W., Margaret T. Lee, Constance M. Horgan, and Andrea Acevedo. "Adapting Washington Circle Performance Measures for Public Sector Substance Abuse Treatment Systems." Journal of Substance Abuse Treatment36, no. 3 (2009): 265-77. doi:10.1016/j.jsat.2008.06.008. 


\section{International Conference on Advanced Research in SOCIAL SCIENCES}

March 7-9,2019, London - United Kingdom

Gerdtham, Ulf-G., and Mickael Löthgren. "On Stationarity and Cointegration of International Health Expenditure and GDP." Journal of Health Economics 19, no. 4 (2000): 461-75. doi:10.1016/s0167-6296(99)00036-3.

Grusky, David B., Bruce Western, and Christopher Wimer. The Great Recession. New York: Russell Sage Foundation, 2011a.

Grusky, David B., Bruce Western, and Christopher Wimer. "The Consequences of the Great Recession." In The Great Recession, 3-20. New York: Russell Sage Foundation, 2011b.

Grusky, David B., and Katherine R. Weisshaar. Social Stratification Class, Race, and Gender in Sociological Perspective. Boulder, CO: Westview Press, A Member of the Perseus Books Group, 2014.

Krugman, Paul, and Robin Wells. "The Slump Goes On: Why?" The New York Review of Books, 2010. https://www.nybooks.com/articles/2010/09/30/slump-goes-why/.

Lago-Peñas, Santiago, David Cantarero- Prieto, and Carla Blázquez-Fernández. "On the Relationship between GDP and Health Care Expenditure: A New Look." Economic Modelling 32 (2013):

124-29.

https://www.sciencedirect.com/science/article/pii/S0264999313000242?via=ihub.

Lo, Celia C., and Tyrone C. Cheng. "Racial/ethnic Differences in Access to Substance Abuse Treatment." Journal of Health Care for the Poor and Underserved22, no. 2 (2011): 621-37.

Lo, Celia C., Tyrone C. Cheng, and Rebecca J. Howell. "Problem Drinking's Associations with Social Structure and Mental Health Care: Race/Ethnicity Differences." Journal of Psychoactive Drugs46, no. 3 (2014): 233-42. doi:10.1080/02791072.2014.887161.

Mezuk, B., J. A. Rafferty, K. N. Kershaw, D. Hudson, C. M. Abdou, H. Lee, W. W. Eaton, and J. S. Jackson. "Reconsidering the Role of Social Disadvantage in Physical and Mental Health: Stressful Life Events, Health Behaviors, Race, and Depression." American Journal of Epidemiology 172, no. 11 (2010): 1238-249. doi:10.1093/aje/kwq283.

Mirowsky, John, and Catherine E. Ross. Social Causes of Psychological Distress. 2nd Edition ed. Hawthorne, NY: Walter De Gruyter, 2003.

Moos, Rudolf H. "Active Ingredients of Substance Use-focused Self-help Groups." Addiction103, no. 3 (2008): 387-96. doi:10.1111/j.1360-0443.2007.02111.x.

Narayan, Paresh Kumar, and Seema Narayan. "Does Environmental Quality Influence Health Expenditures? Empirical Evidence from a Panel of Selected OECD Countries." Ecological Economics 65, no. 2 (2008): 367-74. doi:10.1016/j.ecolecon.2007.07.005.

National Bureau of Economic Research. "Business cycle dating committee, Business Cycle Dating Committee." National Bureau of Economic Research, 2010. http://www.nber.org/cycles/sept2010.html

"National Healthcare Disparities Report, 2011." PsycEXTRA Dataset, 2011. doi:10.1037/e579292012-001.

Pearlin, Leonard I., Elizabeth G. Menaghan, Morton A. Lieberman, and Joseph T. Mullan. "The Stress Process." Journal of Health and Social Behavior22, no. 4 (1981): 337-56. doi:10.2307/2136676. 


\section{International Conference on Advanced Research in SOCIAL SCIENCES}

March 7-9,2019, London - United Kingdom

Pearlin, Leonard I. "The Sociological Study of Stress." Journal of Health and Social Behavior30, no. 3 (1989): 241. doi:10.2307/2136956.

Sheikh, Aziz. "Why Are Ethnic Minorities Under-Represented in US Research Studies?" PLoS Medicine 3, no. 2 (2005). doi:10.1371/journal.pmed.0030049.

Sinha, Rajita. "Chronic Stress, Drug Use, and Vulnerability to Addiction." Annals of the New York Academy of Sciences1141, no. 1 (2008): 105-30. doi:10.1196/annals.1441.030.

Substance Abuse and Mental Health Services Administration. Detoxification and Substance Abuse Treatment. . Publication no. Treatment Improvement Protocol (TIP) Series, No. 45. HHS Publication No. (SMA) 13 4131. Rockville, MD, 2006.

Tenorio, Kimberly A., and Celia C. Lo. "Social Location, Social Integration, and the Cooccurrence of Substance Abuse and Psychological Distress." The American Journal of Drug and Alcohol Abuse37, no. 4 (2011): 218-23. doi:10.3109/00952990.2011.568079.

The TOPPS-II Interstate Cooperative Study Group. "Drug Treatment Completion and Postdischarge Employment in the TOPPS-II Interstate Cooperative Study." Journal of Substance Abuse Treatment 25, no. 1 (2003): 9-18. doi:10.1016/s0740-5472(03)00050-3.

U.S. Department of Health and Human Services. Treatment Episode Data Set-Discharges (TEDS-

D) Series-Concatenated. Report. Inter-university Consortium for Political and Social Research. ICPSR 30122-v5 2006-2011. Ann Arbor, MI, 2015.

Volkow, Nora. "Intervening Early to Prevent Substance Use Disorders." Huffington Post, March 10, 2016. https://www.huffingtonpost.com/nora-volkow/intervening-early-toprev_b_9429190.html.

Wahler, Elizabeth A. The Relationship of Social Stress, Economic Hardship, and Psychological Distress to Addiction Severity among Kentucky Substance Abuse Treatment Participants. PhD diss., University of Kentucky, College of Social Work, 2012. Lexington, KY: UKnowledge. http://uknowledge.uky.edu/cgi/viewcontent.cgi?article=1000\&context=csw_etds

Walton, Maureen A., Thomas M. Reischl, and Chathapuram S. Ramanathan. "Social Settings and Addiction Relapse." Journal of Substance Abuse7, no. 2 (1995): 223-33. doi:10.1016/08993289(95)90006-3.

Walton, Maureen A., Frederic C. Blow, C. Raymond Bingham, and Stephen T. Chermack. "Individual and Social/environmental Predictors of Alcohol and Drug Use 2 Years following Substance Abuse Treatment." Addictive Behaviors28, no. 4 (2003): 627-42. doi:10.1016/s03064603(01)00284-2.

Williams, David R., Selina Mohammed, Jacinta Leavell, and Chiquita Collins. "Race, Socioeconomic Status, and Health: Complexities, Ongoing Challenges, and Research Opportunities." Annals of the New York Academy of Sciences 1186 (2010): 69-101. doi:10.1111/j.1749-6632.2009.05339.x.

World Health Organization. "Substance Abuse." World Health Organization. October 05, 2017. http://www.who.int/topics/substance_abuse/en/. 
International Conference on Advanced Research in SOCIAL SCIENCES March 7-9, 2019, London - United Kingdom 


\section{International Conference on Advanced Research in SOCIAL SCIENCES}

March 7-9,2019, London - United Kingdom

Table 1. Descriptive Statistics of Variables Used for Successful Discharge Status among US Adults, 2006-2011 TEDS-D-Concatenated, 2006 to 2011 (N=1,678,915)

\begin{tabular}{|c|c|c|}
\hline Predictors & $\begin{array}{l}\text { Perc } \\
\text { ent }\end{array}$ & $\begin{array}{l}\text { Standard } \\
\text { Deviation }\end{array}$ \\
\hline \multicolumn{3}{|l|}{ Race/Ethnicity } \\
\hline White & $\begin{array}{l}63.3 \\
\%\end{array}$ & 0.48 \\
\hline Black & $\begin{array}{l}18.6 \\
\%\end{array}$ & 0.39 \\
\hline Hispanic & $6.4 \%$ & 0.25 \\
\hline Asian/Pacific Islander & $0.7 \%$ & 0.09 \\
\hline $\begin{array}{l}\text { American Indian, American Native, or } \\
\text { Native Hawaiian }\end{array}$ & $3.6 \%$ & 0.19 \\
\hline Other race & $7.3 \%$ & 0.26 \\
\hline \multicolumn{3}{|l|}{ Region } \\
\hline South & $\begin{array}{l}37.8 \\
\%\end{array}$ & 0.48 \\
\hline Northeast & $\begin{array}{l}11.7 \\
\%\end{array}$ & 0.32 \\
\hline Midwest & $\begin{array}{l}26.0 \\
\%\end{array}$ & 0.44 \\
\hline West & $\begin{array}{l}24.6 \\
\%\end{array}$ & 0.43 \\
\hline Male & $\begin{array}{l}66.2 \\
\%\end{array}$ & 0.47 \\
\hline
\end{tabular}

Primary Substance

Alcohol

$43.7 \quad 0.50$

Cocaine/crack

$\%$

Marijuana/hashish

$9.0 \% \quad 0.29$

$22.5 \quad 0.42$

$\%$

Heroin

$7.6 \% \quad 0.26$

Opiates/synthetics

$6.9 \% \quad 0.25$

Other substances

$10.1 \quad 0.30$

$\%$

No primary substance

$0.3 \% \quad 0.05$ Age

$12-17$ years old

$10.5 \quad 0.31$

$\%$ 


\section{International Conference on Advanced Research in SOCIAL SCIENCES}

March 7-9,2019, London - United Kingdom

$18-24$ years old

2.

$25-34$ years old

$35-44$ years old

$45-54$ years old

55 years old or older

12 or more years of education

Employment Status

Full-time

Part-time

Unemployed

Living Arrangement

Homeless

Dependent living

Independent living

Marital Status

Never married

Currently married

Separated

Divorced, widowed

Health insurance

No insurance

Private insurance

Medicaid

Medicare, or Other Year
$23.1 \quad 0.42$

$\%$

$27.7 \quad 0.45$

$\%$

$19.9 \quad 0.40$

$\%$

$14.3 \quad 0.35$

$\%$

$4.4 \% \quad 0.21$

$62.6 \quad 0.48$

$\%$

$24.3 \quad 0.43$

$\%$

$8.9 \% \quad 0.29$

$66.8 \quad 0.47$

$\%$

$8.4 \% \quad 0.28$

$24.0 \quad 0.43$

$\%$

$67.6 \quad 0.47$

$\%$

$59.6 \quad 0.49$

$\%$

$17.6 \quad 0.38$

$\%$

$5.0 \% \quad 0.22$

$17.9 \quad 0.38$

$\%$

$65.8 \quad 0.47$

$\%$

$13.4 \quad 0.34$

$\%$

$14.3 \quad 0.35$

$\%$

$6.5 \% \quad 0.25$ 


\section{International Conference on Advanced Research in SOCIAL SCIENCES}

March 7-9, 2019, London - United Kingdom

$\begin{array}{lll}2006 & 15.0 & 0.36 \\ & \% & \\ 2007 & 16.5 & 0.37 \\ & \% & \\ 2008 & 18.1 & 0.38 \\ & \% & \\ 2009 & 17.7 & 0.38 \\ & \% & \\ 2010 & 16.5 & 0.37 \\ & \% & \\ 2011 & 16.3 & 0.37 \\ & \% & \\ \end{array}$

Logistic Regression Model Predicting Successful Discharge Status among US Adults, 20062011 TEDS-D-Concatenated, 2006 to $2011(\mathrm{~N}=1,678,915)$

\begin{tabular}{lll}
\hline Predictors & OR & $95 \%$ CI \\
\hline Race (ref.=White) & & \\
Black & $0.85^{* * *}$ & $0.84,0.85$ \\
Hispanic & $1.21^{* * *}$ & $1.19,1.22$ \\
Asian/Pacific Islander & $1.07^{*}$ & $1.04,1.12$ \\
$\quad$ American Indian, American Native, or & $0.89^{* * *}$ & $0.88,0.91$ \\
Native Hawaiian & & \\
$\quad$ Other race & $1.05^{* * *}$ & $1.03,1.06$ \\
Region (ref.=South) & & \\
Northeast & $1.32^{* * *}$ & $1.31,1.34$ \\
Midwest & $0.62^{* * *}$ & 0.61, \\
West & & 0.624 \\
Male & $1.01^{* * *}$ & $1.01,1.02$ \\
Primary Substance (ref.=Alcohol) & $1.09^{* * *}$ & $1.08,1.09$ \\
Cocaine/crack & & \\
Marijuana/hashish & $0.59^{* * *}$ & $0.58,0.59$ \\
Heroin & $0.60^{* * *}$ & $0.60,0.61$ \\
Opiates/synthetics & $0.44^{* * *}$ & $0.43,0.44$ \\
Other substances & $0.47^{* * *}$ & $0.47,0.48$ \\
No primary substance & $0.55^{* * *}$ & $0.55,0.56$ \\
Age (ref.=12-17 years old) & $0.49^{* * *}$ & $0.46,0.52$ \\
18 - 24 years old & & \\
25 - 34 years old & $0.78^{* * *}$ & $0.77,0.79$ \\
35 - 44 years old & $0.80^{* * *}$ & $0.79,0.82$ \\
45 - 54 years old & $0.86^{* * *}$ & $0.85,0.88$ \\
& $0.98^{* *}$ & $0.97,0.99$
\end{tabular}




\section{International Conference on Advanced Research in SOCIAL SCIENCES}

March 7-9, 2019, London - United Kingdom

55 years old or older

12 or more years of education

Employment Status (ref.=Full-time)

Part-time

Unemployed

Living Arrangement (ref.=Homeless)

Dependent living

Independent living

Marital Status (ref.=Never married)

Currently married

Separated

Divorced, widowed

Health insurance (ref.=No insurance)

Private insurance

Medicaid

Medicare, or Other

Year $($ ref.=2007)

2006

2008

2009

2010

2011

$\mathrm{p}<0.005,{ }^{* *} \mathrm{p}<0.01,{ }^{* * * *} \mathrm{p}<0.001$

$\mathrm{OR}$, odds ratio; $\mathrm{CI}$, confidence interval
$1.23^{* * *}$

$1.22^{* * *}$

$1.20,1.25$

$1.21,1.23$

$0.87^{* * *}$

$0.86,0.88$

$0.72^{* * *}$

$0.72,0.73$

$0.93^{* * *}$

$0.91,0.94$

$0.88^{* * * *}$

$0.87,0.89$

$1.02^{* * *}$

$1.01,1.03$

$0.85^{* * *}$

$0.84,0.86$

$0.95^{* * *}$

$0.95,0.96$

$1.19^{* * *}$

1.18

1.203

$0.69^{* * *}$

$0.68,0.70$

$0.91^{\text {*** }}$

$0.90,0.92$

0.99

$0.98,1.01$

$0.99^{*}$

$0.85^{* * *}$

$0.98,0.99$

$0.86^{* * * *}$

$0.84,0.85$

$0.84^{* * *}$

$0.85,0.87$

$0.83,0.85$ 